\title{
An Analysis of the Water Cycle in the Sahel through a Lagrangian Perspective
}

\author{
R. Nieto ${ }^{1,2, *}$, M. Vázquez ${ }^{1}$, I. Algarra ${ }^{1}$ and L. Gimeno ${ }^{1}$ \\ Published: 15 July 2016 \\ 1 Environmental Physics Laboratory (EPhysLab), Facultade de Ciencias, Universidad de Vigo, \\ Ourense, Spain \\ 2 Department of Atmospheric Sciences, Institute of Astronomy, Geophysics and Atmospheric Sciences, \\ University of São Paulo, São Paulo, Brazil \\ * Correspondence: rnieto@uvigo.es; Tel.: +34-988-387-248
}

\begin{abstract}
The Sahelian region is located southern the Sahara Desert and the wet tropical belt of central Africa, and it is affected by a monsoonal regime. It is well known that the Sahel is one of the most vulnerable areas due its annual strong climatic variations. In essence, to bring precipitation over a region, the atmosphere needs moisture to condense. So, it is necessary to know where the supply of moisture that precipitates over the Sahel come from to understand the rainfall variability. In a previous paper by Nieto et al. [1] they defined, using a lagrangian method of diagnosis, the sources of moisture that reach the Sahel $\left(10^{\circ}-20^{\circ} \mathrm{N} ; 20^{\circ} \mathrm{E}-18^{\circ} \mathrm{W}\right)$ calculating changes in the specific humidity along trajectories of a lot of atmospheric-particles. The analysis was done using the observational data from the ECMWF for a 5-year period (2000-2004), but the shorter time period used impeded the study of interannual variability or possible relationships with modes of climate variability as ENSO or NAO. Based in those lacks in this following paper we provide an extensively revisited analysis to determine and analyze in an improved way the sources of moisture for the Sahel. In order to carry out this aim, we have used here: (a) a longer climatological period of time from 1980 to 2012 (three decades) to redefine the sources of moisture; (b) the nowadays best-considered database to reproduce the atmospheric branch of the hydrological cycle: the ERA-Interim Reanalysis data to track atmospheric moisture changes along trajectories; (c) a definition of the sources using a moving threshold in the field of E-P for annual, seasonal and monthly scales. This new extended and improved data allowed us to redo, among others, the time series of E-P day by day calculated backward for the moisture over the Sahel area and integrated over the moisture sources determined in the previous steps. But now the most important is the possibility to analyze the relationship with between the amount of the moisture over the sources and the field of real precipitation over the Sahel, and to have concrete outcomes about the modulation by the main patterns of climate variability on the sources as ENSO, NAO and the local West African Monsoon (WAM).
\end{abstract}

Keywords: Sahel, water cycle, moisture sources, lagrangian approach, climate variability

\section{Introduction}

The Sahelian region is a land strip located in northern Africa and which extends from the Atlantic Ocean in the West to the Red Sea in the East. This region represents a transition area between the Sahara Desert, located to the north, and the African savannah to the south. The precipitation pattern over the region is linked to the Intertropical Convergence Zone (ITCZ), which is located further north in the boreal summer, and affected by a monsoonal regime, with with a regime of precipitations that reaches $600 \mathrm{~mm}$ (during August) from a minimum of $200 \mathrm{~mm}$. Trade winds are predominant in this region. These NE wind flows, known as Harmattan winds, are dry and cold 
The 1st International Electronic Conference on Atmospheric Sciences (ECAS 2016), 16-31 July 2016;

Sciforum Electronic Conference Series, Vol. 1, 2016

fluxes with high dust content. On summer months (monsoon season) the intense warming on the surface causes a thermal low which changes the wind regime favoring the entrance of air masses from the Gulf of Guinea. These air masses bring moisture to the Sahelian region [2]. Previous studies, realized for the 5-years period 2000-2004 [1], identified local evaporation processes (recycling) as the main moisture source for the area, and the Gulf of Guinea, North Atlantic ocean, and Mediterranean sea were detected as moisture sources too.

The Sahel is in the crosshairs of climate research by the fact that the region is affected by periods of longer droughts and several stronger precipitations. In the last part of the 20th century-from the 1970s and most of the 80s and continued with some interruptions into the 90s-the Sahel region experienced the phenomenon namely 'the desiccation', that is, a long period of sustained declining precipitation. During 1983 and 1984 the annual rainfall reached the lowest values ever recorded over the region. This pattern of rainfall regulates the agriculture production and the population needs to have the capacity to adapt its life to these higher fluctuations.

In essence, to bring precipitation over a region, the atmosphere needs moisture to condense. So, it is necessary to know where the supply of moisture that precipitates over the Sahel come from to understand the rainfall variability. Although the Sahel refers to the complete W-E African latitudinal strip $15^{\circ} \mathrm{N}$ centered, in this work we will analyze the western region $\left(10^{\circ}-20^{\circ} \mathrm{N} ; 20^{\circ} \mathrm{E}-18^{\circ} \mathrm{W}\right)$ as it represents the area most vulnerable to climate variability (as in [1]). In the previous paper by Nieto et al. [1], using a lagrangian method of diagnosis, they were detected the sources of moisture that reaches the Sahel calculating changes in the specific humidity along trajectories of a lot of atmospheric-particles. The analysis was done using the observational data from the ECMWF for a 5-year period (2000-2004), but the shorter time period used impeded the study of interannual variability or possible relationships with modes of climate variability as ENSO or NAO. Based in those lacks in this following paper we provide an extensively revisited analysis to determine and analyze in an improved way the sources of moisture for the Sahel. In order to carry out this aim, we have used here: (a) a longer climatological period of time from 1980 to 2012 (three decades) to redefine the sources of moisture; (b) the nowadays best-considered database to reproduce the atmospheric branch of the hydrological cycle: the ERA-Interim Reanalysis data to track atmospheric moisture changes along trajectories; (c) a definition of the sources using a moving threshold in the field of E-P for annual, seasonal and monthly scales. This new extended and improved data allowed us to redo, among others, the time series of E-P day by day calculated backward for the moisture over the Sahel area and integrated over the moisture sources determined in the previous steps. But now the most important is the possibility to analyze the relationship with between the amount of the moisture over the sources and the field of real precipitation over the Sahel, and to have concrete outcomes about the modulation by the main patterns of climate variability on the sources as ENSO, NAO and the local West African Monsoon (WAM).

\section{Experiments}

The methodology used in this work is based on the lagrangian particle dispersion model FLEXPART v9.0. This model was developed by Stohl et al. [3] to study the dispersion of pollutants in the atmosphere and adapted for the estimation of the surface freshwater flux [4,5]. The analysis was carried out using data from 1980 to 2012 obtained from the ERA-Interim reanalysis of the ECMWF [6] available on a regular $1^{\circ} \times 1^{\circ}$ horizontal grid and with 61 vertical levels (from the surface to $0.1 \mathrm{hPa}$ ). This reanalysis is considered the best for the study of the atmospheric branch of the hydrologic cycle.

FLEXPART divides the atmosphere in approximately 2 millions of particles. The methodology allows us to reproduce the trajectory of the particles reaching a target area by knowing the three-dimensional wind speed (among other variables and several parametrizations). Moisture variations at every moment are calculated taking into account variations in the specific humidity (q), being this value registered every $6 \mathrm{~h}$. 
The 1st International Electronic Conference on Atmospheric Sciences (ECAS 2016), 16-31 July 2016;

Sciforum Electronic Conference Series, Vol. 1, 2016

Throughout $(\mathrm{q})$ changes in time, increases and decreases in the particle moisture along its trajectory can be analyzed by the following equation:

$$
(\mathrm{e}-\mathrm{p})_{\mathrm{k}}=\mathrm{m} \cdot(\mathrm{dq} / \mathrm{dt})
$$

being $\mathrm{m}$ the mass of the particle, e evaporation and $\mathrm{p}$ precipitation, which represent moisture increases and decreases respectively.

The total surface freshwater flux (E-P) for a specific area A is obtained by adding individual (e-p) values for the total amount of particles in the atmospheric column within that area (A).

Those areas showing positive $(\mathrm{E}-\mathrm{P})$ values $[(\mathrm{E}-\mathrm{P})>0]$ represent sources of moisture, where particles gain moisture; and those showing negative (E-P) values are defined as moisture sinks, where particles loss moisture. This methodology can be applied forward or backward in time, however in this work we will use only the second option and we will follow backward trajectories of particles reaching the Sahel for a period of 10 days (mean time of residence for water vapor, Numaguti).

\section{Results}

\subsection{Climatic Identification of Sources of Moisture}

The Sahelian region in this study is defined between $10^{\circ}$ and $20^{\circ} \mathrm{N} \mathrm{y} 16^{\circ} \mathrm{W}$ and $20^{\circ} \mathrm{E}$ (green box in Figure 1). Analyzing backward trajectories from this area is possible to localize where moisture reaching the Sahel comes from. Figure 1 shows (E-P) values integrated for the 10 days for the 33-years period, it provides information about total annual integrated contribution. Reddish colors represent areas where $(\mathrm{E}-\mathrm{P})>0$, and therefore they are sources regions, whereas bluish colors represent areas where $(\mathrm{E}-\mathrm{P})<0$ and are considered as sink areas. So, we can distinguish between 6 main moisture sources: North Atlantic Ocean (NAtl), the Gulf of Guinea (GGuinea), Mediterranean Sea (Med), Northeaster Africa (NEAf), Central Eastern Africa (CEAf) and the Sahelian region (Sahel). NAtl, GGuinea, CEAf, and NEAf were defined as moisture sources taking into account a threshold of $0.10 \mathrm{~mm} /$ day. For the Mediterranean Sea the complete basin was considered and the Sahel moisture source was selected by its own limits $\left(10^{\circ}-20^{\circ} \mathrm{N} ; 16^{\circ} \mathrm{W}-20^{\circ} \mathrm{E}\right.$, black box on Figure 1). (E-P) the pattern is very robust and shows, in general, the same distribution when a seasonal analysis is applied.

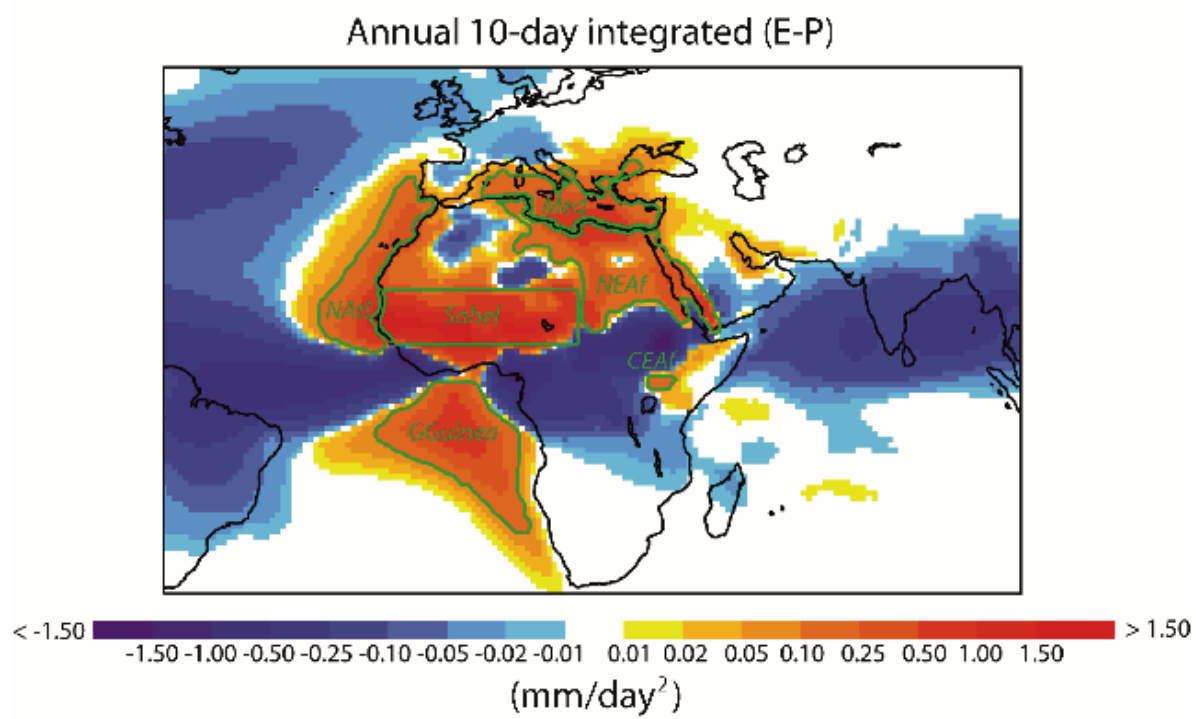

Figure 1. Climatological annual average of 10-day integrated (E-P) obtained through the backward sahel experiment for the period 1980-2012. The green contour lines indicate the source areas selected.

Figure 2 shows seasonal (E-P) values integrated for the 10 days period backward in time. Seasons were defined taking into account the central month for the monsoon regime, which has its 
peak in August. So, the monsoon season (summer) is defined as July, August, and September (JAS); winter corresponds to January-February-March (JFM), the pre-monsoon season (spring) with April-May-June (AMJ), and the post-monsoon season (autumn) with October-November-December (OND). Although mentioned above, the moisture pattern is very robust along the year, some seasonal difference related to ITCZ location can be detected. Those are related to moisture losses on the ITCZ, which are mainly located over the Atlantic Ocean and Africa during autumn, showing a weak expansion toward the Pacific Ocean in winter. In spring, the ITCZ expands toward the Indian ocean and Indonesia, whereas in the Atlantic ocean it does not appear. In summer, the ITCZ is more intense over Asia. This behavior agrees with the Western Africa monsoon's cycle.

Local evaporation process (recycling) over the Sahel constitutes the main moisture source for all the seasons. In winter, NAtl and Med sources are also very influent too, and GGuinea to a lesser degree. On the pre-monsoon season (spring) NEAf source intensifies its contribution, and GGuinea gains importance. During summer, the precipitation over the region are more intense and major discrepancies on moisture sources appear.
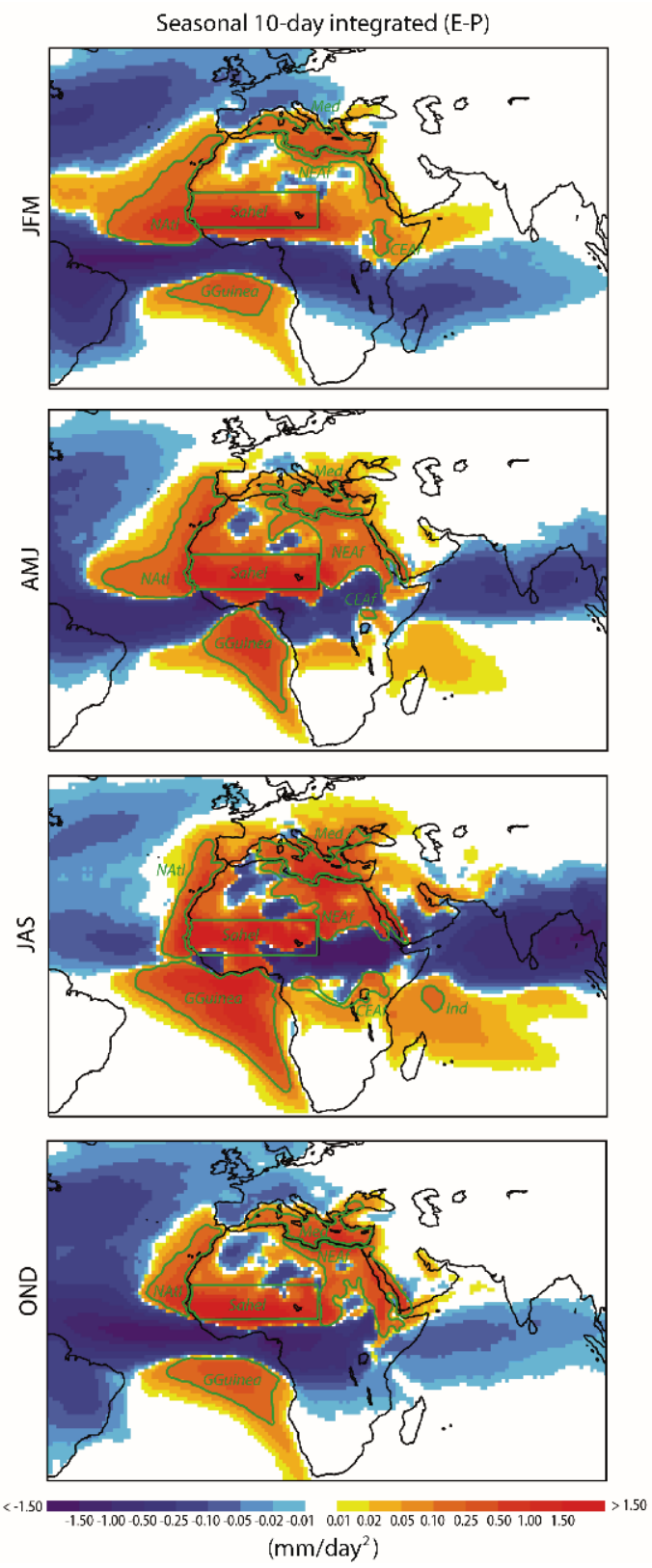

Figure 2. As Figure 1, but in a seasonal scale. 
The 1st International Electronic Conference on Atmospheric Sciences (ECAS 2016), 16-31 July 2016; Sciforum Electronic Conference Series, Vol. 1, 2016

\subsection{Moisture Sources Contribution}

The lagrangian methodology applied in this study allows quantifying the moisture transport day by day from each source. Figure 3 shows the annual moisture contribution (E-P) from every source (as defined in Figure 1, with the exception of the Ind source which only appears during monsoon season).

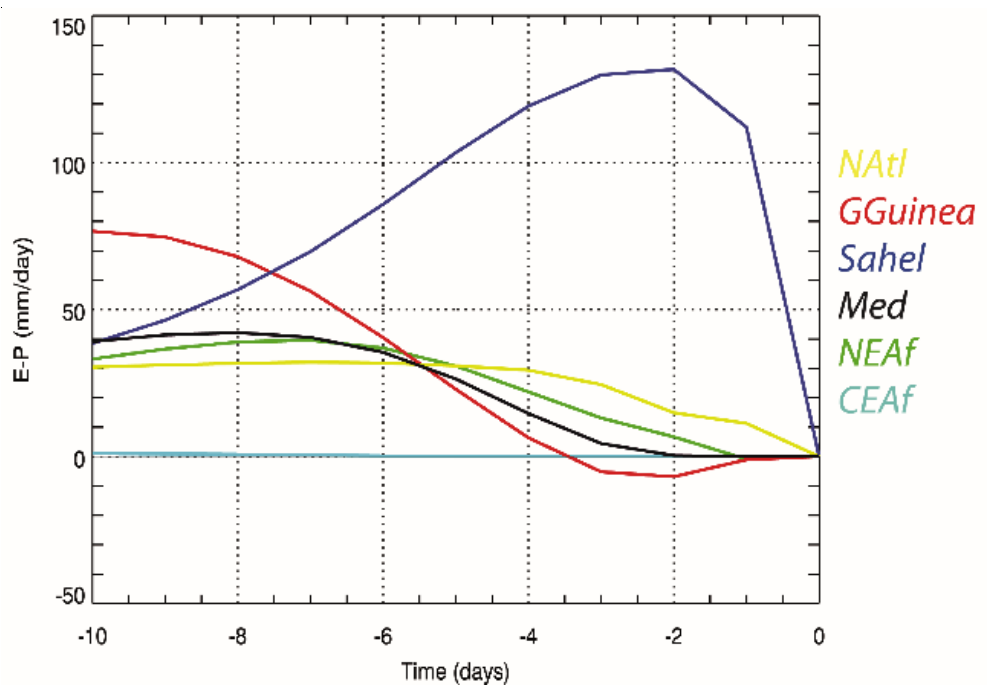

Figure 3. Annual time series of E-P calculated backward during 10 days for the Sahel region for the moisture transported from each source.

Sahel (dark blue line) is the source with the greatest moisture contribution to the target area from the first to the seventh day before the particles reach it, being their maximum contribution on the second day (131.8 mm/day). From the seventh day GGuinea (red line) overtakes Sahel contribution, being the most important source until the tenth day. It is important to notice that GGuinea does not act as a real source until the fourth day back, being before a moisture sink. NAtl moisture source (yellow line) supplies moisture form the first to the last day, being its contribution almost constant since the fourth day, and reaching the maximum contribution on the seventh day (32.1 mm/day). Med (black line) and NEAf (green line) show a similar behavior. They supply moisture from the second day, and their greatest moisture contribution occurs on the eight ( $42.2 \mathrm{~mm} /$ day) and seventh (39.6 mm/day) day. CEAf (light blue line) shows the lowest contribution due to its small area, being its contribution positive from the fifth day.

A seasonal analysis of (E-P) time series for 10 days of backward trajectories is shown in Figure 4, but the limit for the sources of moisture are now those defined in Figure 2 for each season. The criteria to delimited them are the same that for the annual moisture sources. Sahel moisture source (dark blue line) is the main source for every season, being its pattern a little bit different on the monsoon season (JAS). In general Sahel is the predominant source on first days of transport. CEAf (light blue line) has the lower contribution. The remaining sources show a greater seasonal variability.

On the monsoon season (JAS) the Indian ocean appears as a new source (orange line) and the other sources shows a greater variability. Sahel continues being predominant source most of the days before the particles reach the target region. However, an important difference appears on the first day when this source acts as a sink. Due to the shift in the wind flow during the monsoon, a south-southeast flow appears, favoring moisture entrance from GGuinea. This situation makes this last source the predominant one from the sixth day, increasing their contribution until the tenth day. During summer NAtl contribution (yellow line) is positive over the whole period, showing a maximum value on the third day. NEAf and Med have a similar behavior and their contribution become more relevant on the second and third day, respectively. CEAf and Ind have a positive moisture contribution along the ten days, however, their contribution is very small compared with the other sources. 
The 1st International Electronic Conference on Atmospheric Sciences (ECAS 2016), 16-31 July 2016; Sciforum Electronic Conference Series, Vol. 1, 2016
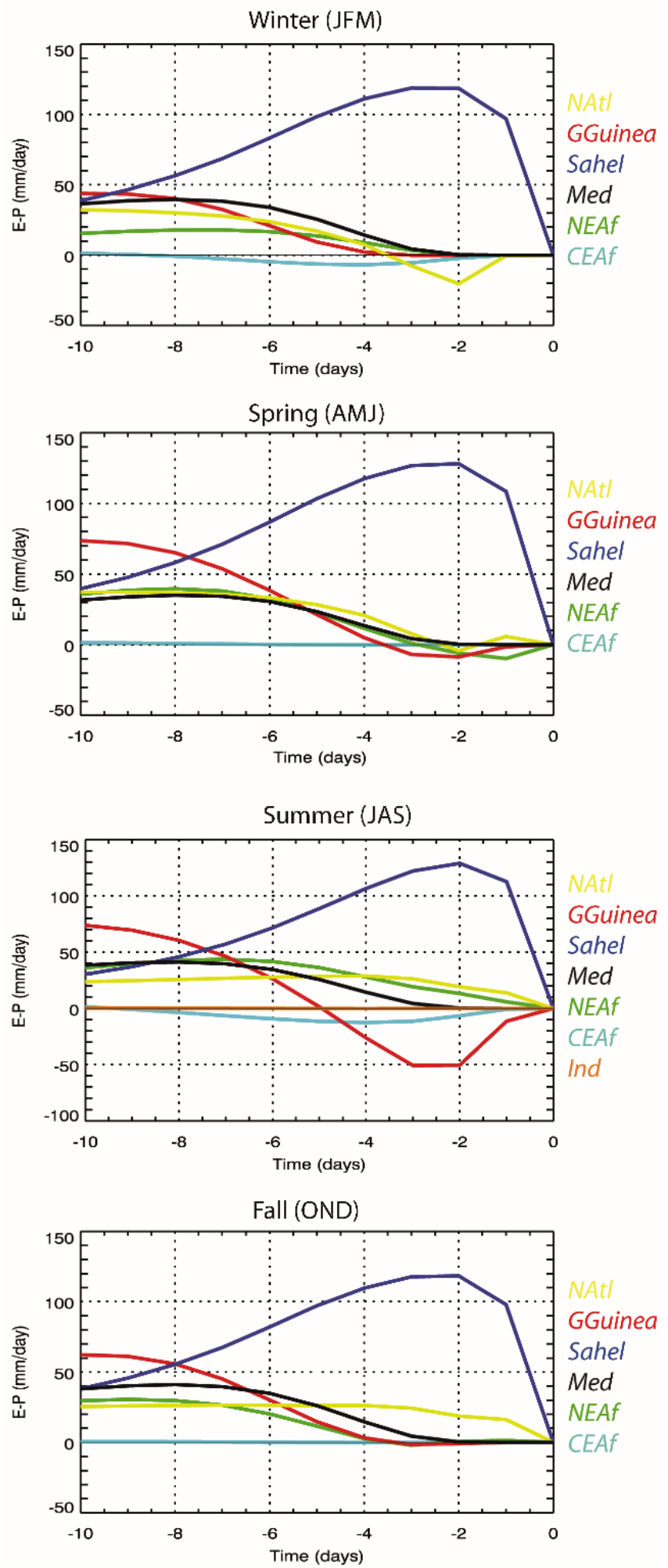

Figure 4. As Figure 3, but using the limits for the seasonal source of moisture defined in Figure 2.

\subsection{Teleconnection Patterns Influence over the Sources of Moisture}

The following section is an analysis of linear correlations (Pearson) between some of the main teleconnection patterns, as the North Atlantic Oscillation (NAO), the phenomenon of El Niño-Southern Oscillation (ENSO) and the West African Monsoon is performed (WASM), with the (E-P) time series for the moisture sources for the Sahel region during the 33-year period. 
The 1st International Electronic Conference on Atmospheric Sciences (ECAS 2016), 16-31 July 2016; Sciforum Electronic Conference Series, Vol. 1, 2016

Although the signal of the NAO appears along the whole year, it is in winter when the index is stronger, so we have realized correlations only for this season (JFM). In the case of ENSO it has influence throughout the complete year on a global scale, so we used the annual indices: Niño3.4 and SOI, for the ocean and atmospheric components. Finally, WASM index was used to correlate during July to September (JAS), when it has the maximum values [7-9].

Negative significant correlations (significance level at 95\%) with NAO were obtained with the GGuinea source and positive significant correlation (99\%) with NEAf and Med. With Niño3.4 was obtained a significant negative correlation (99\%) with Med, and SOI shows a negative correlation with NEAf and positive with Med ( $90 \%$ significance level in both cases). Finally, WASM index shows a negative significant correlation with NEAf $(99 \%)$ and with CEAF and Med (95\%) sources.

\section{Conclusions}

Main sources of moisture to the Sahel region for the study period of 33 years (1980-2012) were identified. This sources, on an annual scale, are the Sahel itself through local evaporation processes, the Gulf of Guinea, the North Atlantic, the Northeast region of Africa, the Mediterranean Sea and the area of East Central Africa. On a seasonal scale, a new source of moisture over the Indian Ocean appears during the summer (monsoon season, JAS).

The annual study shows that the main source of moisture for the Sahel region is the recycling, followed by the moisture from the Gulf of Guinea that appears as the second dominant source because of its influence during the monsoon season. North Atlantic, Northeast Africa, and the Mediterranean basin have a similar contribution as a moisture source. Finally, the last source of moisture in importance for the Sahel region is the continental central East Africa source, which supplies a quite little quantity of moisture to the Sahel target area due to its smaller area in comparison with the other ones.

An analysis of backward trajectories day by day reveals that the Sahel itself is the dominant source of moisture (trough recycling) during the nearest days of transport to the target area, and this source is only overtaken by the Gulf of Guinea source on the seventh day before the particles reach the Sahel, when GGuinea becomes dominant. When a seasonal analysis is performed, the local evaporation processes (recycling) remains the most important during winter (JFM), spring (AMJ) and autumn (OND). However, in summer (JAS), which coincides with the monsoon season, recycling is displaced by the Gulf of Guinea moisture source.

Due to the extended period of study that has been considered in this work (1980-2012), it has been able to study the relationship between the main climate teleconnection patterns and the (E-P) series over the sources of moisture using a linear correlation (Pearson coefficient). It was found that with NAO during winter (JFM) there is a negative significant correlation with the moisture supply from the Gulf of Guinea, and a positive one North East Africa and the Mediterranean moisture sources. Significant negative (positive) correlations between Niño3.4 (SOI) and the Mediterranean source were also obtained. SOI also seems to influence the moisture transport from North East Africa in a negative sense. The West African Monsoon (WAM) shows negative significant correlations with East Central Africa, North Africa, and the Mediterranean sources.

Acknowledgments: Raquel Nieto acknowledges the support of the Spanish government through the funding of the TRAMO (CGL-2012-35485) project, which is also funded by FEDER (European Regional Development Fund), and the CNPq grant 314734/2014-7 by the Brazilian government.

Author Contributions: R.N. and L.G. conceived and designed the experiments; I.A. performed the experiments; R.N. and I.A. analyzed the data; M.V. contributed analysis tools; R.N. wrote the paper.

Conflicts of Interest: The authors declare no conflict of interest. The founding sponsors had no role in the design of the study; in the collection, analyses, or interpretation of data; in the writing of the manuscript, and in the decision to publish the results. 
The 1st International Electronic Conference on Atmospheric Sciences (ECAS 2016), 16-31 July 2016;

Sciforum Electronic Conference Series, Vol. 1, 2016

\section{Abbreviations}

The following abbreviations are used in this manuscript:

$\begin{array}{ll}\text { AMJ } & \text { April-May-June } \\ \text { CEAf } & \text { Central Eastern Africa } \\ \text { E } & \text { Evaporation } \\ \text { ECMWF } & \text { European Centre for Medium-Range Weather Forecasting } \\ \text { ENSO } & \text { El niño-Southern Oscillation } \\ \text { FLEXPART } & \text { FLEXible PARTicle dispersion model } \\ \text { GGuinea } & \text { Gulf of Guinea } \\ \text { ITCZ } & \text { Inter Tropical Convergence Zone } \\ \text { JAS } & \text { July-August-September } \\ \text { JFM } & \text { January-February-March } \\ \text { Med } & \text { Meditrarranean } \\ \text { NAO } & \text { North Atlantic Oscillation } \\ \text { NAtl } & \text { North Atlantic } \\ \text { NE } & \text { Northeastern } \\ \text { NEAf } & \text { North Eastern Africa } \\ \text { OND } & \text { October-November-December } \\ \text { P } & \text { Precipitation } \\ \text { SOI } & \text { Southern Oscilation Index } \\ \text { WAM } & \text { West African Monsoon }\end{array}$

\section{References}

1. Nieto, R.; Gimeno, L.; Trigo, R.M. A Lagrangian identification of major sources of Sahel moisture. Geophys. Res. Lett. 2006, 33, L18707, doi:10.1029/2006GL027232.

2. Nicholson, S.E. The West African Sahel: A Review of Recent Studies on the Rainfall Regime and Its Interannual Variability. ISRN Meteorol. 2013, 2013, 453521.

3. Stohl, A.; Hittenberger, M.; Wotawa, G. Validation of the Lagrangian particle dispersion model FLEXPART against large scale tracer experiment data. Atmos. Environ. 1998, 32, 4245-4264.

4. Stohl, A.; James, P. A Lagrangian analysis of the atmospheric branch of the global water cycle: Part 1: Method description, validation, and demonstration for the August 2002 ooding in central Europe. J. Hydrometeorol. 2004, 5, 656-678.

5. Stohl, A.; James, P. A Lagrangian analysis of the atmospheric branch of the global water cycle. Part II: Earth's river catchments, ocean basins, and moisture transports between them. J. Hydrometeorol. 2005, 6, 961-984, doi:10.1175/JHM470.1.

6. Dee, D.P.; Uppala, S.M.; Simmons, A.J.; Berrisford, P.; Poli, P.; Kobayashi, S.; Andrae, U.; Balmaseda, M.A.; Balsamo, G.; Bauer, P.; et al. The ERA-Interim reanalysis: Configuration and performance of the data assimilation system. Q. J. R. Meteorol. Soc. 2011, 137, 553-597, doi:10.1002/qj.828.

7. Li, J.; Zeng, Q. A unied monsoon index. Geophys. Res. Lett. 2002, 29, 1-4.

8. Li, J.P.; Zeng, Q.C. A new monsoon index and the geographical distribution of the global monsoons. Adv. Atmos. Sci. 2003, 20, 299-302.

9. Li, J.P.; Zeng, Q.C. A new monsoon index, its interannual variability and relation with monsoon precipitation. Clim. Environ. Res. 2005, 10, 351-365.

(C) 2016 by the authors; licensee MDPI, Basel, Switzerland. This article is an open access article distributed under the terms and conditions of the Creative Commons by Attribution (CC-BY) license (http://creativecommons.org/licenses/by/4.0/). 